\title{
NÍVEIS DE PRODUÇÃO EM VINHEDOS DE ALTITUDE DA CV. MALBEC E SEUS EFEITOS SOBRE OS COMPOSTOS FENÓLICOS ${ }^{1}$
}

\author{
LEONARDO CURY DA SILVA ${ }^{2}$, AIKE ANNELIESE KRETZSCHMAR $^{3}$, LEO RUFATO ${ }^{3}$, \\ ALBERTO FONTANELLABRIGHENTI ${ }^{4}, \mathrm{CAROLINE} \mathrm{SCHLEMPER}^{5}$
}

RESUMO - O presente trabalho teve como objetivo obter informações sobre a evolução dos compostos fenólicos, de acordo com o nível de raleio de cachos, durante a maturação de uvas cv. Malbec, de modo a estabelecer critérios que contribuam para definir o manejo mais apropriado ao vinhedo. Os ensaios foram conduzidos durante as safras de 2005/06 e 2006/07, em um talhão do vinhedo Villa Francioni, no município de São Joaquim - Santa Catarina, com videiras da cultivar Malbec, enxertadas sobre 'Paulsen 1103' conduzidas em espaldeira, com espaçamento de 3,0m x 1,2m e cobertura antigranizo. Os níveis de raleio de cachos, ajustados na virada de cor "véraison", corresponderam a $13 \mathrm{tha}^{-1}$ (Testemunha), $11 \mathrm{tha}^{-1}$ (T1), $9 \mathrm{t} \mathrm{ha}^{-1}$ (T2) e $7 \mathrm{t} \mathrm{ha}^{-1}$ (T3), compondo um delineamento em blocos casualizados. Avaliou-se a evolução dos compostos fenólicos durante as oito semanas antecedentes à colheita, conforme os três níveis de raleio. Dos resultados obtidos, conclui-se que, para as condições de altitude, a prática de raleio de cachos influencia na composição fenólica das bagas da cultivar Malbec, aumentando o conteúdo de antocianinas facilmente extraíveis para um tratamento de raleio de cachos com uma produção esperada de aproximadamente $10 \mathrm{t} \mathrm{ha}^{-1}$, melhorando a composição fenólica das bagas, atributos favoráveis à produção de vinhos tintos finos amplos e estruturados.

Termos para Indexação: Vitis vinifera L., raleio de cachos, polifenóis totais, qualidade do vinho.

\section{LOAD LEVELS IN VINEYARDS OF MALBEC CV. AND THEIR EFECTS ON EVOLUTION AND FENOLIC MATURATION}

ABSTRACT - The present work had as objective to get information on the phenolic compounds evolution and anthocyanin contents in the berries of grapes, in accordance with the level of clusters thinning, during the maturation to establish criteria that contribute to define the most appropriate management to the vineyard. This experiment was carried out in 2005/06 and 2006/07 seasons, in a commercial vineyard of Villa Francioni in São Joaquim city, State of Santa Catarina, Southern Brazil. The 'Malbec' vineyard was carried in a vertical trellis system, in a 3,0m x 1,2m spacing and covering. The levels of clusters thinning, adjusted in the "véraison," corresponded to $13 \mathrm{tha}^{-1}$ (Control), $11 \mathrm{t} \mathrm{ha}^{-1}$ (T1), $9 \mathrm{t} \mathrm{ha}^{-1}$ (T2) and $7 \mathrm{t} \mathrm{ha}^{-1}$ (T3). It was evaluated the evolution of phenolic content during the eight antecedent weeks of harvest on the effect of the three levels of clusters thinning in the quality of the berries. The results showed that, in altitude conditions, the practical of clusters thinning influences in the phenolic content of the 'Malbec' berries. The level production of $10 \mathrm{tha}^{-1}$, increased the phenolic and anthocyanin contents, favorable attributes to the production of ample and structuralized wines.

Index terms: Vitis vinifera L., cluster thinning, phenolic contents, wine quality.

\section{INTRODUÇÃO}

A qualidade da uva e, conseqüentemente, do vinho são resultados da interação de numerosos fatores, entre os quais se ressaltam aspectos biológicos (cultivar, clone e porta-enxerto), físicos (classe estrutural e textural do solo), climáticos (temperatura, pluviosidade e luz), sanitários e culturais (sistema de condução, poda, manejo da vegetação, raleio de cachos e densidade de plantação) (Loret et al., 2003).

A uva 'Malbec' é uma casta de $V$. vinifera de antiga existência na França. No Brasil, seu cultivo é ainda pouco expressivo, sendo cultivada principalmente no Rio Grande do
Sul, onde foi relacionada entre as cultivares vinificadas. Possui cachos médios, piramidais, alados e bem soltos, bagas pretas, esféricas, de médias a grandes, polposas, muito doces e de maturação precoce (Sousa, 2002).

$\mathrm{Na}$ região de São Joaquim, a altitude elevada (1.200 a $1.400 \mathrm{~m}$ ) proporciona elevada amplitude térmica com temperaturas noturnas amenas. Essas baixas temperaturas influenciam no metabolismo da videira, retardando o amadurecimento dos frutos, reduzindo o crescimento das plantas e permitindo maturação fenólica mais completa (Rosier et al., 2004).

O raleio ou remoção de cachos é uma, prática agronômica dentre outras, que podem influenciar na produtividade e qualidade dos mostos e dos vinhos. (Reynolds \& Wardle, 1989;

\footnotetext{
'(Trabalho 242-07). Recebido em: 04-10-2007. Aceito para publicação em: 15-02-2008.

${ }^{2}$ Eng. Agrônomo, Mestrando em Produção Vegetal, Centro de Ciências Agroveterinárias - CAV, Universidade Estadual de Santa Catarina - UDESC, Departamento de Agronomia e-mail: a6lc@cav.udesc.br. Bolsista CAPES

${ }^{3}$ Eng. Agrônomo(a), Doutor(a), Professor(a), Departamento de Agronomia CAV-UDESC, C.P.281, CEP 8852-000, Lages-SC, e-mail: a2aak@cav.udesc.br ${ }^{4}$ Acadêmico de Agronomia CAV-UDESC, Bolsista de Iniciação Científica.

${ }^{5}$ Eng. Agrônoma, CAV-UDESC.
} 
Amati et al.,1994; Amati et al., 1995).

Através da eliminação de cachos, busca-se regular a produção de frutos, visando à melhoria da qualidade dos mostos e dos vinhos. O raleio de cachos pode ser considerado como uma correção do excesso de carga deixada na poda, visto que cada planta e cultivar não deveriam suportar mais carga frutífera que aquela que possa conferir qualidade e desenvolvimento compatíveis ao seu vigor (Hidalgo, 1993).

Devido à grande importância econômica aplicada aos componentes fenólicos, os quais fazem parte do vinho tinto, é importante compreender as interações e variações destes compostos resultantes das técnicas de manejo aplicadas ao vinhedo, maturação dos frutos e características inerentes à cultivar (Kennedy, 2003).

No período da vinificação, as antocianinas e os polifenóis totais são extraídos das películas durante a fermentação tumultuosa, e sua extração natural ocorre em solução aquosa de etanol, entre 12 e $14 \% \mathrm{v} \mathrm{v}^{-1}$, produzido pelo mosto durante a fermentação (Iland et al., 2004).

A qualidade sensorial das bagas e dos vinhos está estreitamente relacionada com as antocianinas acumuladas nas bagas, as quais se acumulam exclusivamente na película (Ribéreau-Gayon et al., 1998). A antocianina é o componente fenólico responsável pela cor do vinho tinto e, para a maioria das cultivares de uva, é restrita à película. Iniciando em "véraison" (virada de cor), as antocianinas acumulam-se nas bagas da uva acompanhando a acumulação dos açúcares. Existem evidências de que o início do declínio das antocianinas ocorre ao final do desenvolvimento das bagas, aparentemente coincidindo com o murchamento, próximo à sobrematuração (Kennedy et al., 2000).

Alguns estudos têm mostrado boa relação entre a análise do potencial fenólico das bagas e a densidade corante do vinho, assim como sua qualidade e intensidade específica descritiva de seus aromas (Iland et al., 2004).

Atualmente, é praticamente indiscutível o efeito que tem o raleio de cachos na composição fenólica e na qualidade da uva e do vinho. Alguns trabalhos descrevem que, quanto maior a intensidade de raleio de cachos, maior o incremento no acúmulo de compostos fenólicos, em especial para as antocianinas, em diversas cultivares e condições de manejo (Reynolds \& Wardle, 1989; Amati et al., 1994; Amati et al., 1995; Heygel.,1996). Contudo, Villegas (2003) não observou efeitos significativos da intensidade e época de raleio de cachos sobre as características cromáticas (intensidade de cor) e fenólicas (polifenóis totais e antocianinas). Outros autores (Lavezzi et al., 1995; Schalkwyk et al., 1996) também não encontraram efeitos positivos significativos do raleio de cachos sobre a qualidade das bagas, se comparado às videiras sem ralear.

Devido à importância da cultivar Malbec em vinhos tintos finos varietais ou em cortes com outras cultivares e à pouca disponibilidade de informações em condições de altitude acima de 900 metros, realizou-se o presente trabalho para avaliar o efeito dos diferentes níveis de produção em vinhedos da cv. Malbec e seus efeitos sobre a evolução da maturação dos frutos e seus compostos fenólicos.

\section{MATERIAL E MÉTODOS}

Os ensaios foram conduzidos durante as safras de 2005/ 06 e 2006/07, em um talhão do vinhedo de propriedade da Villa Francioni, coordenadas $28^{\circ} 17^{\prime} 39^{\prime \prime} \mathrm{S}$ e $49^{\circ} 55^{\prime} 56^{\prime \prime} \mathrm{W}$, a 1.230 metros de altitude, localizado no município de São Joaquim, Santa Catarina. Foi utilizado um vinhedo da cv. Malbec, com plantas de três anos de idade, uniformes em vigor e desenvolvimento, enxertadas sobre 'Paulsen 1103', espaçadas de 3,0 x 1,2 m, orientadas N-S, conduzidas em espaldeira vertical e podadas em cordão esporonado duplo, a 1,2 m de altura e cobertas com clarite coloração branca de proteção antigranizo.

Os tratamentos foram ajustados quando $50 \%$ das bagas se encontravam na fase de "véraison" (virada de cor), correspondendo ao dia 30 de janeiro de 2006 e 24 de janeiro de 2007. Calculou-se a carga máxima esperada por planta com base no peso médio dos cachos da temporada anterior, com uma média de $245 \mathrm{~g}$ por cacho e no número médio de 20 cachos por planta, a qual correspondeu à Testemunha (sem raleio) com uma produção estimada de $13 \mathrm{t} \mathrm{ha}^{-1}$. Os raleios foram aplicados a cada tratamento, reduzindo a produtividade em $15 \%$, esperando uma produção de 11 tha $^{-1}$ (T1), em $30 \%$ com produção estimada de 9 t ha $^{-1}$ (T2) e em $45 \%$ estimando produzir $7 \mathrm{tha}^{-1}(\mathrm{~T} 3)$, compondo um delineamento em blocos casualizados, com quatro repetições e 40 plantas por tratamento.

Foram coletadas, quinzenalmente, 300 bagas, localizadas na zona basal, mediana e apical de diferentes cachos, tanto do setor leste como do setor oeste das filas, alcançando uma amostra representativa, segundo metodologia proposta por Rizzon \& Mielle (2002). As análises foram realizadas a partir do início da maturação dos cachos até a colheita, em 10 de abril de 2006 e 9 de abril de 2007, seguindo os padrões da vinícola, quando alcançado um promédio de $20^{\circ}$ Brix na testemunha, utilizando-se das dependências do laboratório do Núcleo de Tecnologia de Alimentos (NUTA) do Centro de Ciências Agroveterinárias (CAV) da Universidade do Estado de Santa Catarina (UDESC).

Para determinar a concentração dos compostos fenólicos, utilizou-se uma subamostra de 50 bagas. As sementes foram retiradas para evitar uma leitura superestimada, atribuída aos taninos duros, contidos no interior das mesmas e não extraídos durante o processo de vinificação. Seguindo metodologia descrita por Iland et al. (2004), utilizou-se uma solução hidroalcoólica de etanol $50 \% \mathrm{v} \mathrm{v}^{-1}$, ajustada a $\mathrm{pH} 2$, simulando a extração das antocianinas e polifenóis totais durante a fermentação alcoólica da vinificação. Essas condições, somadas à agitação constante e ao aquecimento em banho-maria por cinco minutos, extraem aproximadamente $94 \%$ dos compostos fenólicos e é chamada de solução extrato.

A quantificação do aporte fenólico das bagas foi baseada na metodologia proposta por Glories (1998) e Ribéreau-Gayon et al. (1998), através da absorbância característica do ciclo benzênico, componente da maior parte dos polifenóis. Utilizouse $1 \mathrm{~mL}$ de solução extrato diluído em $100 \mathrm{~mL}$ de água destilada realizou-se a leitura em espectrofotômetro. Calculou-se a absorbância do comprimento de onda de $280 \mathrm{~nm}$ em uma cubeta de quartzo de 10,01 $\mathrm{mm}$ de percurso óptico, mediante a fórmula 
IPT $=$ D.O. $280 * \mathrm{f}($ Fator de diluição $)$.

A concentração de antocianinas extraíveis foi estimada segundo a metodologia proposta por Ribéreau-Gayon \& Stonestreet (1965), método químico baseado na propriedade característica das antocianinas, as quais variam sua cor de acordo com o pH. O método mensura a diferença da densidade óptica na absorbância da onda de $520 \mathrm{~nm}$ (D.O. $\left.{ }_{520}\right), \Delta \mathrm{d}^{\prime}=\mathrm{d}{ }_{1}-\mathrm{d}$ ' ${ }_{2}$, em uma cubeta de quartzo de 10,01 mm de percurso óptico. Esse método prevê a preparação das amostras para leitura em espectofotômetro $\mathrm{d}_{1}$ e d' ${ }_{2}$. A primeira amostra ( $\left.\mathrm{d}_{1}\right)$, é composta por $1 \mathrm{~mL}$ de solução extrato, $1 \mathrm{~mL}$ de etanol, $0,1 \% \mathrm{HCl}$ e $10 \mathrm{~mL}$ de $\mathrm{HCl} 2 \%(\mathrm{pH}=0,8)$. A segunda $\left(\mathrm{d}_{2}\right.$ ) contém $1 \mathrm{~mL}$ de solução extrato, $1 \mathrm{~mL}$ de etanol $0,1 \% \mathrm{HCl}$ e $10 \mathrm{~mL}$ de solução tampão $[\mathrm{pH}=3,5(303,5 \mathrm{~mL}$ de fosfato dissódico $0,2 \mathrm{M}+696,5 \mathrm{~mL}$ de ácido cítrico $0,1 \mathrm{M})$ ]. Mediante a fórmula $\mathrm{AE}\left(\mathrm{mg} \mathrm{g}^{-1}\right)=388^{*} \Delta \mathrm{d}^{\prime} /$ peso 50 bagas, obtémse a quantidade de antocianinas facilmente extraíveis em miligrama por grama de matéria fresca.

Os resultados obtidos foram submetidos à análise de regressão realizada ao longo do tempo de maturação dos cachos até a vindima, analisando o comportamento das variáveis segundo os tratamentos de raleio de cachos e suas respectivas produções esperadas.

\section{RESULTADOS E DISCUSSÃO}

A maturação fisiológica dos frutos teve início na virada de cor (30-01-06 e 24-01-07), aos 65 dias após a plena floração, e a vindima foi realizada em 10-04-06 e 09-04-07. Considerando os parâmetros que definem as características fenólicas, como o conteúdo de antocianos facilmente extraíveis (AFE) e índice de polifenóis totais (IPT) das bagas, verificou-se que houve efeito significativo da intensidade de raleio sobre as características assinaladas.

Observa-se uma tendência quadrática na evolução das antocianinas, durante as safras 2005/06 e 2006/07 (Figura 1). O ponto médio máximo de concentração de antocianos extraíveis ocorreu nos tratamentos T1 e T2, em ambas as safras. Na Figura 1A, durante a safra 2005/06, esses pontos de máxima concentração ocorreram aos 52 dias após a virada de cor DAV, com um acúmulo de 6,53 e 6,84 $\mathrm{mg} \mathrm{g}^{-1}$ de baga para $\mathrm{T} 1 \mathrm{e} \mathrm{T} 2$, respectivamente. $\mathrm{Na}$ Figura 1B, durante a safra 2006/07, os pontos de máxima em T1 e T2 ocorreram aos 57 e $52 \mathrm{DAV}$, com uma concentração de AFE de 5,32 e $5,67 \mathrm{mg} \mathrm{g}^{-1}$ de baga, respectivamente. Pode-se notar que o período de acúmulo dos antocianos nas bagas difere entre os tratamentos, sendo ligeiramente maior nos tratamentos T1 e T2, os quais possuem maior concentração de AFE. Em média, após $52 \mathrm{DAV}$, em ambas as safras, houve redução na concentração antociânica das bagas, divergindo do descrito por Saint-Criq de Gaulejac et al. (1998), os quais descrevem um aumento linear no acúmulo de antocianos facilmente extraíveis. Contudo, Arismendi (2003) também constatou redução nestas concentrações durante a maturação da uva, na cultivar Carmenère, após 45 DAV.

De acordo com Iland et al. (2004), a concentração desses glicosídeos nas bagas das cultivares 'Syrah' e 'Cabernet Sauvignon' pode variar entre 0,5 e $3,5 \mathrm{mg} \mathrm{g}^{-1}$ de bagas; já na cv. 'Pinot Noir', pode variar entre 0,2 e $1,4 \mathrm{mg} \mathrm{g}^{-1}$ de bagas. Como demonstrado na Figura 3, observa-se que o acúmulo de antocianinas facilmente extraíveis comportou-se de forma quadrática na vindima, segundo os níveis de raleio aplicados durante as duas safras do ensaio. Os índices de antocianinas nas bagas alcançaram concentrações muito superiores ao descrito por Iland et al. (2004), chegando a $5,47 \mathrm{mg} \mathrm{g}^{-1}$ de baga em 2006 (Figura 3A) e 5,16 $\mathrm{mg} \mathrm{g}^{-1}$ de baga em 2007 (Figura 3B), divergindo do descrito por Lavezzi et al. (1995), Schalkwyk et al. (1996) e Villegas (2003), que não observaram diferenças significativas entre os níveis de raleio, demonstrando haver grande potencial de cor para os vinhos produzidos com essas uvas em condições de altitude. Pode-se observar nas curvas de regressão polinomial, Figuras 3A e 3B, que a máxima concentração de AFE foi alcançada para um nível de raleio de cachos cuja produção esperada é estimada em $10 \mathrm{t} \mathrm{ha}^{-1}$ para ambas as safras.

Pode-se constatar, na Figura 2, durante as safras de 2005/ 06 e 2006/07, que a concentração de polifenóis totais nas bagas se comportou de forma quadrática na Testemunha e no T3, diferindo dos tratamentos intermediários de raleio de cachos $\mathrm{T} 1$ e T2, os quais apresentam comportamentos lineares durante a maturação fenólica dos frutos. Aos 52 DAV os tratamentosTestemunha e T3 proporcionaram seus níveis máximos de IPT, com valores de $\left(\mathrm{I}_{280}\right)$ de 54,22 e 53,90 (Figura 2A), em 2006, e aos 53 DAV, um índice de 67,38 e 68,61 (Figura 2B) em 2007, respectivamente. Após essa data, houve acentuada redução nos índices de polifenóis totais para os tratamentos extremos de raleio de cachos. Por outro lado, os tratamentos T1 e T2 alcançaram seus máximos índices de polifenóis totais somente na vindima, em ambas as safras, demonstrando ainda ter potencial de acúmulo de IPT em sobrematuração. Pode-se constatar, na Figura 3, que a concentração de polifenóis totais, na vindima, comportou-se de forma quadrática, segundo os níveis de raleio aplicados em suas produções estimadas durante as duas safras do ensaio. Amelhor média de IPT foi alcançada com uma produção estimada de 10 t ha $^{-1}$ nas safras de 2005/06 (Figura 3A) e 2006/07 (Figura 3B), alcançando valores de 63,98 e 92,76, respectivamente. Esses valores diferem das citações de Lavezzi et al. (1995), Schalkwyk et al. (1996) e Villegas (2003), que não observaram diferenças significativas entre os níveis de raleio para IPT.

Segundo Hernándes (2004), uvas com IPT acima de 60 devem ser destinadas à elaboração de vinhos de reserva e grande reserva, IPT entre 55 e 45 de vinhos jovens e uvas com IPT abaixo de 40 produzem vinhos considerados medíocres. Pode-se observar, na Figura 3A, que a vinificação de uvas provindas de uma produção estimada em torno de $10 \mathrm{t} \mathrm{ha}^{-1}$ na safra de 2005/06, pode produzir vinhos destinados à reserva, alcançando melhores condições para seu envelhecimento, conferindo maior potencial de guarda (Palliotti et al., 2000), sem a necessidade de concentração do mosto a frio. Esse aumento na concentração fenólica também pode ser observado na safra de 2006/07, chegando a 92,76, para uma produção estimada em torno de $10 \mathrm{t}$ ha $^{-1}$ (Figura 3B). No ano de 2007, as condições climáticas proporcionaram maior índice de doenças, como o mofo-cinzento e a podridão-da-uva madura próximo à vindima. Um dos sistemas de defesa da planta contra o desenvolvimento de agentes fitopatógenos é a síntese de substâncias fungistáticas, incluindo 
polifenóis. Compostos fenólicos que têm demonstrado atividade antimicrobiana são os taninos e o ácido tânico (Beuchat, 2001). $\mathrm{O}$ aumento na incidência de doenças pode ter elevado a concentração de taninos na película e nas bagas, elevando o IPT acima de 60 nos tratamentos com produção estimada abaixo de $13 \mathrm{tha}^{-1}$.

Esse aumento no conteúdo de antocianinas e polifenóis totais nas uvas com uma produção esperada de $10 \mathrm{t} \mathrm{ha}^{-1}$, pode ser atributo de uma modificação no padrão de distribuição de carboidratos, por apresentar melhor relação folha:fruto de 2,45 $\mathrm{m}^{2} \mathrm{Kg}^{-1}$ de fruto. Segundo Alleweldt \& Fader, citados por Casteran (1971), a qualidade das bagas é afetada quando o número de folhas situadas distalmente for inferior a oito ou dez, por ser necessária uma superfície foliar de $2,14 \mathrm{~m}^{2} \mathrm{Kg}^{-1}$ de fruto para um bom equilíbrio nutricional na planta. $\mathrm{O}$ mesmo não foi observado no T3, por haver alta relação $3,47 \mathrm{~m}^{2} \mathrm{Kg}^{-1}$ de fruto, pode ter proporcionado um redirecionamento dos carboidratos à parte aérea ou um aumento no sombreamento sobre das folhas internas
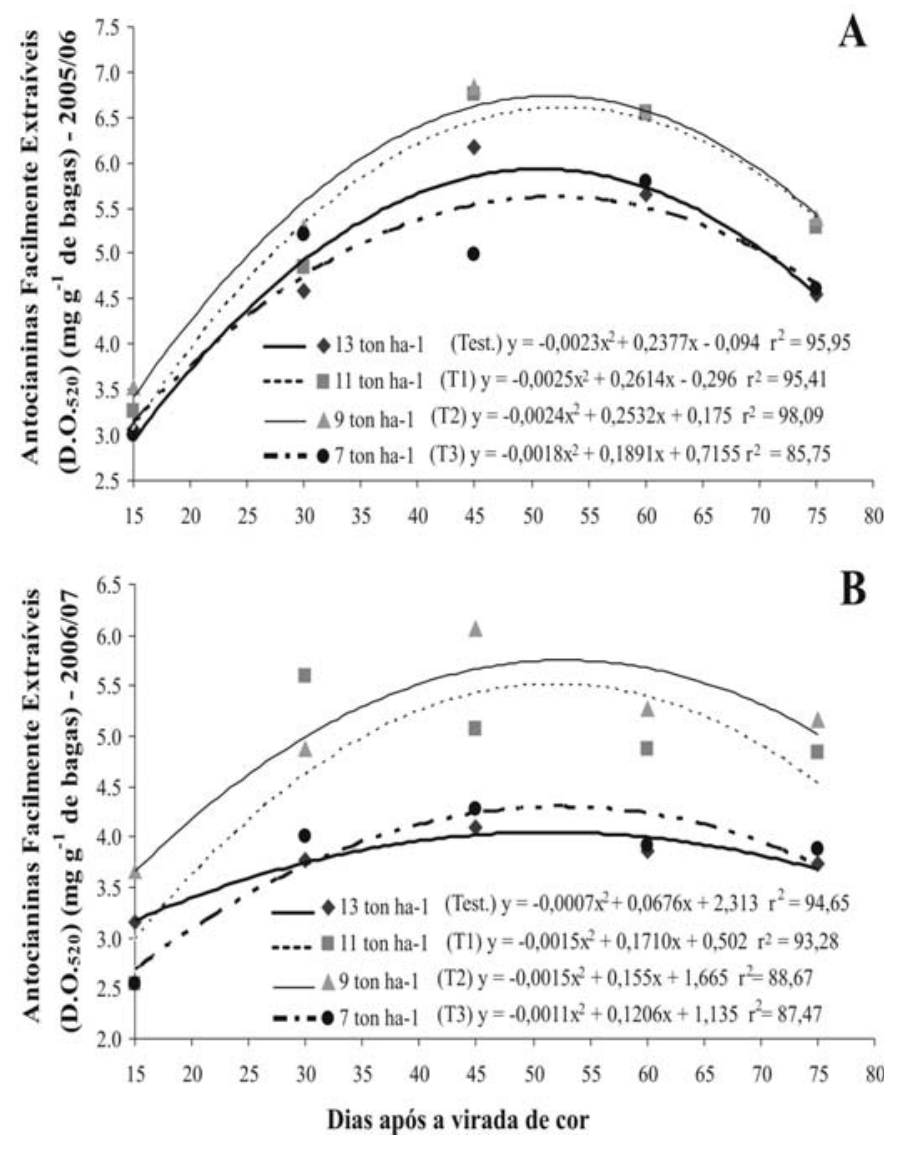

FIGURA 1- Evolução das antocianinas facilmente extraíveis das bagas (AFE) ( $\mathrm{mg} \mathrm{g}^{-1}$ de bagas), durante a safra de 2005/06 (A) e durante a safra de 2006/07 (B), submetidas aos diferentes tratamentos de raleio de cachos, entre os 15 e 75 dias após a virada de cor (véraison). do dossel, reduzindo a capacidade fotossintética e reduzindo o acúmulo de fotoassimilados nos cachos. Na Testemunha, a carga excessiva proporcionou baixa relação folha:fruto de $1,86 \mathrm{~m}^{2} \mathrm{Kg}^{-1} \mathrm{de}$ fruto, o que pode ter influenciado negativamente no equilíbrio nutricional da parreira.

A não-realização de raleio de cachos na safra de 2005/06, para uma produção esperada de $13 \mathrm{t} \mathrm{ha}^{-1}$, ocasionou uma alternância de produção na safra de 2006/07 no talhão experimental. A falta de conhecimento desses fatores para as regiões de altitude de Santa Catarina pode levar à interpretação de resultados contraditórios, como aqueles descritos por diversos autores. Assim, é importante realizar novos estudos com a utilização do raleio de cachos como ferramenta de redução de produção em vinhedos de outras cultivares, para a melhor compreensão das relações entre o manejo agronômico e uma maturação mais uniforme e desejada para a produção de vinhos finos de altitude para guarda.
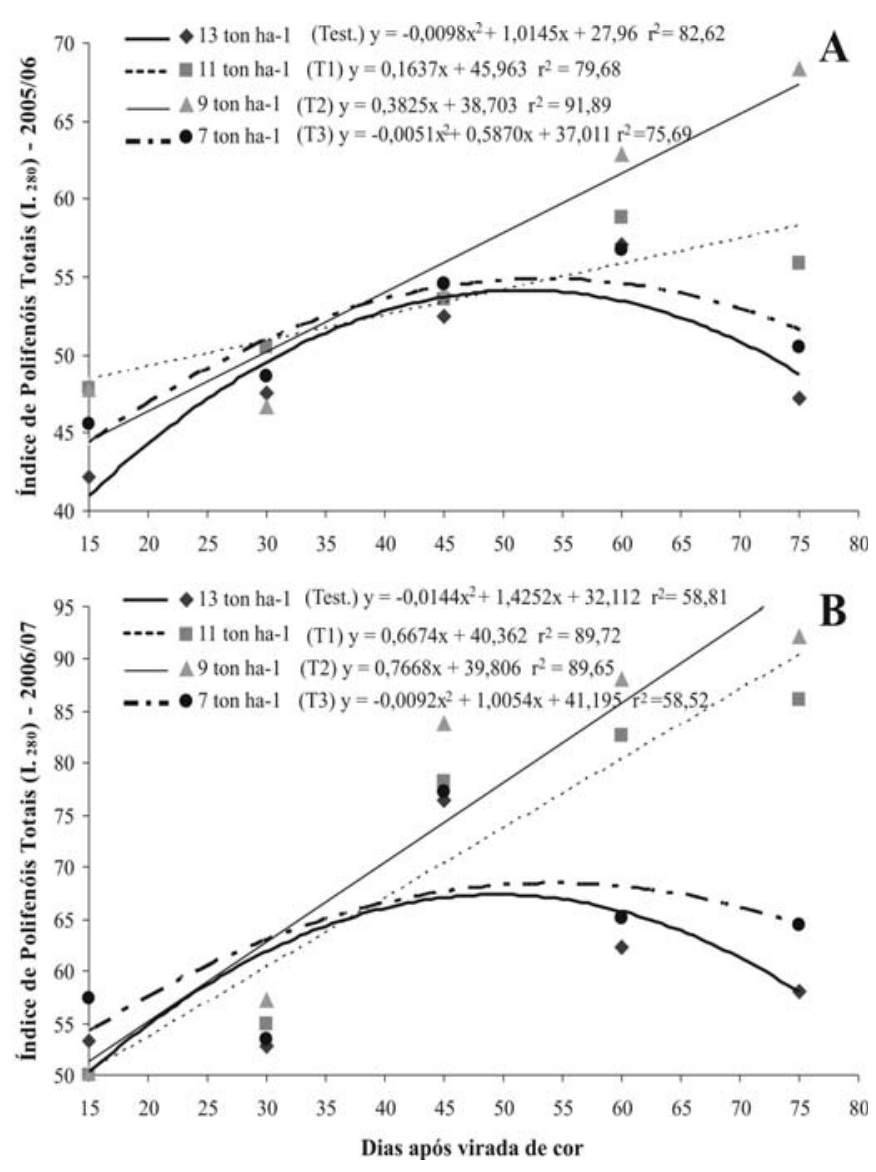

FIGURA 2- Evolução dos polifenóis totais das bagas $\left(\mathrm{I}_{280}\right)$, durante a safra de 2005/06 (A) e durante a safra de 2006/07 (B), submetidas aos diferentes tratamentos de raleio de cachos, entre os 15 e 75 dias após a virada de cor (véraison).

Rev. Bras. Frutic., Jaboticabal - SP, v. 30, n. 3, p. 675-680, Setembro 2008 

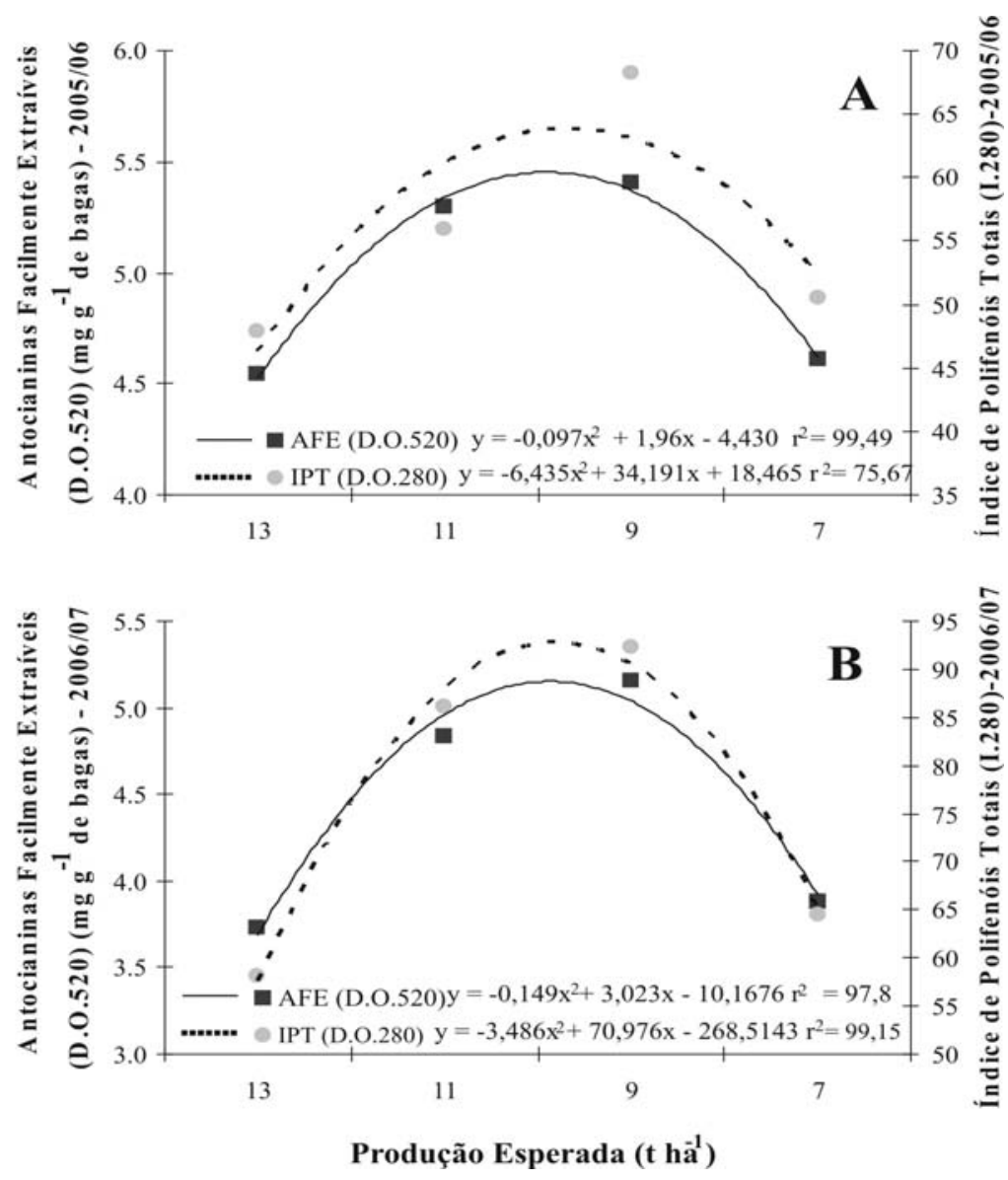

FIGURA 3-Evolução na concentração de antocianinas facilmente extraíveis nas bagas ( $\mathrm{mg} \mathrm{g}^{-1}$ de bagas) e do acúmulo de polifenóis totais $\left(\mathrm{I}_{280}\right)$ de mostos no momento da vindima, temporada de 2005/06 (A) e temporada de 2006/07 (B), segundo as produções estimadas em $t$ ha $^{-1}$.

\section{CONCLUSÕES}

Para a prática de manejo cultural de raleio de cachos na cultivar Malbec, nas condições de 1.230 metros de altitude e de manejo, utilizados nos ensaios nas safras de 2005/06 e 2006/07, pode-se concluir que:

1-A remoção parcial de cachos proporciona aumento na concentração de antocianinas facilmente extraíveis (AFE) e índice de polifenóis totais (IPT) nas bagas.

2-Menor número de cachos por planta, estimando um produção de $10 \mathrm{t} \mathrm{ha}^{-1}$, proporciona melhor desenvolvimento, acúmulo e manutenção dos polifenóis sintetizados desde a virada de cor "veraison" até o momento da vindima.

3-A alta concentração de antocianinas nas bagas para um tratamento com produção esperada de $10 \mathrm{t} \mathrm{ha}^{-1}$, garante uma fruto mais equilibrado em termos de maturação e evolução dos compostos fenólicos, podendo originar vinhos destinados à reserva e grande reserva de guarda.

4-Altos níveis de raleio de cachos, bem como sua ausência, reduzem o acúmulo e a manutenção de polifenóis e antocianos nas bagas, reduzindo a qualidade final dos frutos.

\section{REFERÊNCIAS}

AMATI, A.; MARANGONI, B.; ZIRONI, R.; CASTELLARI, M.; ARFELLI, G. Prove di vendemmia differenziata. Effetti del diradamento dei grappoli: metodiche di campionamento e di analisi delle uve. Rivista di Viticoltura e Enologia, Roma, v.47, p.3-11, 1994.

AMATI, A.; MAZZAVILLANI, G.; ZIRONI, R.; CASTELLARI, M.; ARFELLI, G. Prove di vendemmia differenziata. Effetti del diradamento dei grappoli sulla composizione dei mosti e dei vini. Rivista di Viticoltura e Enologia, Roma, v.48, p.29-37, 1995.

ARISMENDI, P. R. G. Efecto de distintos estados de madurez fenolica sobre la calidad final del vino tinto para los cultivares merlot y carménère durante la temporada 2001-2002. 2003. Talca: Universidad de Talca Facultad de Ciencias Agrárias, 2003. $45 \mathrm{p}$. 
BEUCHAT, L.R. Control of foodborne pathogens and spoilage microorganisms by naturally occurring antimicrobials. In: WILSON, C.L.; DROBY, S. (Ed.). Microbial food contamination. Boca Raton: CRC Press, 2001. cap. 11, p.149-169.

CASTERAN, P. Conduit de la vigne. sciences et techiniques de la vigne. Paris: Editorial Dunot, 1971. v.2, 719 p.

GLORIES, Y. La couleur des vins rouges : les equilibres des anthocyanes et des tanins du Vin. Bordeaux: Actualités, 1998. 417 .

HEIGEL, K. P. Pruning level, thinning and sward and effects on grapes yield and wine quality. California: Rebe Und Wein, 1996. v.48, 328p.

HERNÁNDES, M. R. Medida del color de la uva y del vino y los polifenoles por espectrofotometría. In: Curso de Viticultura para Aficionados en 20 lecciones . Haro: La Rioja, 2004.

HIDALGO, L. Tratado de viticultura. Santiago de Chile: MundiPrensa, 1993.170p.

ILAND, P.; BRUER, N.; EDWARDS, G.; WEEKS, S.; WILKES, E. Chemical analyses of grapes and wine: techniques and concepts. Australia: Campbelltown, 2004.48p.

KENNEDY, J. A.; TROUP, G. J.; PILBROW, J. R.; HUTTON, D. R.; HEWITT, D.; HUNTER, C. R.; RISTIC, R.; ILAND, P. G., JONE, G. P. Development of seed polyphenols in berries from Vitis vinifera L. cv. Shiraz. Australian Journal of Grape an Wine Research, California, v.6, p. 244-254, 2000.

KENNEDY, J. A. Development of berry (seed \& skin) phenolics during maturation, the effect of water status and variety. In: CONGRESO LATINOAMERICANO DE VITICULTURA E ENOLOGÍA, 9., 2003, Santiago. Anais... Santiago: Pontificia Universidad Católica de Chile, 2003.159-164p.

LAVEZZI, A.; RIDOMI, A.; PEZZA, L.; INTRIERI, C.; SILVESTRONI, O. Effetti del diradamento dei grappoli sul rendimento quali-quantitativo Della cv Prosecco (Vitis vinifera L.) allevata a sylvoz. Rivista di Viticoltura e Enologia, Roma, v.48, p.35-40, 1995.

LORET,A.; BOIDO, E.; CARRAU,F.; DISEGNA, E.; MENENDEZ, M.; DELLACASA, E. Avaliação dos conteúdos e perfil de conteúdos antociânicos durante a maturação de uvas Tannat com respeito a outras variedades tintas. In: CONGRESO LATINOAMERICANODE VITICULTURAEENOLOGÍA, 9., 2003, Santiago. Anais... Santiago: Pontificia Universidad Católica de Chile, 2003.64p.
PALLIOTTI, A.; CARTECHINI, A.; POSSINGHAM, J. V.; NEILSEN, G. H. Cluster thinning effects on yield and grape composition in different grapewine cultivars. Acta Horticulturae, Wageningen, v.512, p.111-119, 2000.

REYNOLDS, A. G.; WARDLE, D. A. Impact of various canopy manipulation techniques on growth, yield, fruit composition, and wine quality of gewürztraminer. Journal of Enology and Viticulture, California, v.40, p.121-129, 1989.

RIBEREAU-GAYON, P.; STONESTREET, E. Sciences et techniques du Vin. $2^{\text {td }}$ ed. Paris: Editorial Dumond, 1965.176p.

RIBEREAU-GAYON, P.; DONÈCHE, B.; DUBORDIEU, A.; LONVAUD, A. Traide d'enologie: microbiologie du vin: vinifications. Paris: Editorial Dunod, 1998. 185p.

RIZZON, L. A.; MIELLE, A. Avaliação do cv. Cabernet Sauvignon para a elaboração de vinho tinto. Ciência e Tecnologia de Alimentos, Campinas, v.22, n.2, p.192-198, 2002.

ROSIER, J. P.; BRIGUENTI, E.; SCHUCK, E; BONIN, V. Comportamento da variedade Cabernet Sauvignon cultivada em vinhedos de altitude em São Joaquim - SC. In: CONGRESSO BRASILEIRO DE FRUTICULTURA, 8., 2004, Florianópolis. Anais... 2004.

SAINT CRICQ de GAULEJAC, N ; VIVAS, N. ; GLORIES, Y. Maturation phénolique des raisines rouges. Relation avec la qualité des vins. Comparison des cépages Merlot et Tempranillo. Progres Agricole et Viticole, Paris, v.115, p.316-318, 1998.

SCHALKWYK, D.; VILLIERS, F. E.; FOUCHÉ, G. W. Timing of cluster thinning in grapewines. California: Wynboer Tegnies, 1996. p.121-129.

SOUSA, J. S. I. Viticultura brasileira: principais variedades e suas características. Piracicaba: FEALQ, 2002.368p.

VILLEGAS, M. M. S. Efecto del raleo de inflorescencias y racimos en envero sobre el desarrollo vegetativo, productividad y calidad del mosto y vino en el cv. Carménère (Vitis vinifera L.). 2003. 37 f. Tesis (Doutorado) - Departamento de Fruticultura y Enologia, Facultad de Agronomía, Pontificia Universidad Católica de Chile, Santiago, 2003. 